Ethos: Jurnal Penelitian dan Pengabdian kepada Masyarakat, Vol 9, No.2, Juni 2021: 237-247

\title{
Demonstration Plot Pemanfaatan Pekarangan untuk Ketahanan Pangan KELOMPOK WANITA TANI DI TASIKMALAYA
}

\section{${ }^{1}$ Tini Sudartini, ${ }^{2}$ Rendra Gumilar, ${ }^{3}$ Vivi Indah Bintari, ${ }^{4}$ Deasy Lestary Kusnandar}

\author{
${ }^{1}$ Fakultas Pertanian, Universitas Siliwangi, Jawa Barat, Indonesia, \\ ${ }^{2}$ Fakultas Keguruan dan Ilmu Pendidikan, Universitas Siliwangi, Jawa Barat, Indonesia, \\ ${ }^{3,4}$ Fakultas Ekonomi, Universitas Siliwangi, Jawa Barat, Indonesia \\ email: ${ }^{1}$ tinisudartini@unsil.ac.id, ${ }^{2}$ rendragumilar@unsil.ac.id, ${ }^{3}$ vivi.indah@unsil.ac.id, \\ ${ }^{4}$ deasylestary@unsil.ac.id
}

\begin{abstract}
The impact of the Covid-19 pandemic is felt by all levels of society, one of them are Hegarasri farmer group in Cigalontang, Tasikmalaya and the Sabilulungan farmer group in Tamansari, Tasikmalaya. The problems experienced by the two groups of women farmers are that they do not have sufficient land area, inadequate capital and human resources of members who are not technology literate. So that women farmer groups find it difficult to utilize the resources they have. PbM-KP activities that have been carried out by demonstration plots in the yards and gardens around the Hegarasri farmer group, covering an area of $100 \mathrm{~m} 2$. The vegetable demonstration plots consisted of: sweet potatoes, cassava, scallions, sosin, tomatoes and cayenne pepper. And there is The demonstration plot for sweet corn. The method of implementing PbM-KP activities orally by learning theory in the classroom accompanied by questions and answers, providing assistance costs for the practice of demonstration plot of sweet corn and vegetables, and practice of packaging. The conclusion of the activities are: 1. Provision of working capital assistance for land clearing in the form of plant production facilities. From the harvest, which will be used for planting capital for the following season. 2. Assistance in creating a social media account platform is intended for publication of kwt and poktan which are useful for marketing the products produced. 3. Increasing knowledge of plant cultivation to increase crop production, packing farm products to increase selling value.
\end{abstract}

Keywords: PbM-KP, Yard, Food Security.

\begin{abstract}
Abstrak.. Abstrak. Dampak pandemi Covid-19 dirasakan oleh semua lapisan masyarakat, salah satunya adalah kelompok wanita tani Hegarasri di Cigalontang Tasikmalaya dan kelompok tani Sabilulungan di Tamansari Tasikmalaya. Permasalahan yang dialami oleh kedua kelompok wanita tani tersebut, yaitu tidak mempunyai kecukupan luas tanah, modal yang belum memadai dan sumber daya manusia anggota yang belum melek teknologi. Sehingga, kelompok wanita tani merasa kesulitan dalam memanfaatkan sumber daya yang dimiliki. Kegiatan PbMKP yang telah dilaksanakan demplot di lahan pekarangan dan kebun sekitar kediaman KWT Hegarasri seluas: 100 bata. Demplot sayuran terdiri dari: ubi jalar, singkong, bawang daun, sosi, tomat, dan cabe rawit, serta terdapat pula demplot jagung manis. Metode pelaksanaan kegiatan PbM-KP secara lisan dengan pembelajaran teori di dalam kelas disertai tanya jawab, pemberian biaya bantuan untuk praktik demplot jagung manis dan sayuran, serta praktik packaging-nya. Kesimpulan dari kegiatan ini, sebagai berikut: 1) Pemberian bantuan modal kerja untuk pembukaan lahan berupa sarana produksi tanaman. Dari hasil panennya, yang akan digunakan untuk modal tanam musim berikutnya. 2) Pendampingan pembuatan platform akun media sosial ditujukan untuk publikasi kwt dan poktan yang berguna untuk pemasaran produk yang dihasilkan. 3) Peningkatan pengetahuan budidaya tanaman untuk meningkatkan produksi tanaman, packing produk usaha tani untuk meningkatkan nilai jual.
\end{abstract}

Kata Kunci: PbM-KP, Lahan Pekarangan, Ketahanan Pangan. 


\section{Pendahuluan}

Kelompok Wanita Tani Hegarsari berlokasi di Kampung Cibaeud Desa Lengkongjaya, Kecamatan Cigalontang Kabupaten Tasikmalaya. Berdiri sejak tahun 2019 dengan jumlah anggota tani sebanyak 50 orang. Program kegiatan yang dilakukan oleh Kelompok Wanita Tani Hegarsari meliputi pemanfaatan lahan pekarangan dengan tanaman pangan, tanaman hortikultura, pengembangan UMKM dan demplot pangan mandiri (Hegarsari, 2019).

Sementara itu, Kelompok Wanita Tani Sabilulungan berlokasi di Kelurahan Sumelap, Kecamatan Tamansari Kota Tasikmalaya resmi dibentuk tahun 2007 dengan anggota tani sebanyak 46 orang. Kelompok wanita tani dibentuk bertujuan untuk bersosialisasi, bertukar fikiran, memudahkan koordinasi antar petani, sehingga dapat memacu petani dalam mengembangkan usaha taninya, lebih aktif dalam penyuluhan agar dapat mengubah pola pikir petani. Berusaha tani lebih baik, hidup lebih baik, dan bermasyarakat lebih baik. Kegiatan usaha tani yang dijalankan memanfaatkan lahan pekarangan dan kebun yang berupa lahan kering meliputi usaha tani komoditas palawija, mentimun, kacang panjang, ubi jalar, singkong bengkoang, sayuran, dan padi sawah. Bidang kegiatan tersebut dikoordinasikan oleh pengurus Sub bidang yang terdiri dari Sub bidang Pangan, Peternakan dan Hortikultura. (Sabilulungan, 2017)

Status sosial ekonomi pada kedua kelompok (Kelompok Wanita Tani Hegarsari dan Sabilulungan) ratarata berada pada tingkat ekonomi sosial rendah sampai sedang dan hanya sedikit yang memiliki status sosial ekonomi yang bisa dikatakan tinggi. Hal tersebut, memakai kriteria berdasarkan luas kepemilikan tanah. Berdasarkan wawancara langsung rata-rata kepemilikan tanah di kedua kelompok wanita tani tersebut kurang dari 0,5 ha dan hanya sedikit sekali yang memiliki di atas 1 ha. Sedangkan, luas usaha tani yang diperlukan untuk bisa mencapai titik impas pendapatan sama dengan modal, yaitu masing-masing untuk usaha tani padi, jagung dan kedelai berturut turut 0,52 ha, 0,41 ha, dan 0,46 ha (Susilowati \& Maulana, 2012).

Permasalahan yang terjadi pada kelompok wanita tani tersebut adalah tidak mempunyai kecukupan luas tanah, modal yang belum memadai, dan sumber daya manusia anggota yang belum melek teknologi. Sampai saat ini lahan pekarangan dan kebun di kedua kelompok wanita tani belum dimanfaatkan secara maksimal. Hal tersebut disebabkan oleh keterbatasan biaya untuk pembukaan lahan, pengolahan tanah, saprotan dan Alsintan. Sedangkan, peningkatan produksi akan berdampak pada pendapatan pelaku usaha tani dan produk yang dimiliki juga seharusnya dapat dipasarkan dengan maksimal.

Di masa pandemi Covid-19 seharusnya menjadi peluang bagi kelompok wanita tani untuk dapat memasarkan hasil tanamannya karena semua masyarakat membutuhkan konsumsi pangan yang sehat untuk menunjang imunitas tubuh. Namun kenyataannya tidak demikian, yang dialami oleh kedua kelompok (Kelompok Wanita Tani Hegarsari dan Sabilulungan). Produk pertanian hasil usaha taninya hanya sedikit yang terserap oleh pasar ataupun pedagang. Pada pemberlakuan Pembatasan Sosial Berskala Besar (PSBB), produk pertanian hanya terserap dalam jumlah yang sedikit, mengingat terbatasnya konsumen yang belanja di pasar karena adanya keharusan untuk tinggal di rumah serta dilarangnya kerumunan orang 
banyak dalam resepsi pernikahan, pertemuan atau acara lain. Dalam keadaan demikian harga produk pertanian menjadi sangat rendah dan otomatis menurunkan penghasilan pelaku usaha tani. Selain itu juga, produk pertanian kebanyakan tidak bisa disimpan lama dan akan cepat menurun kualitasnya apabila tidak diolah lebih lanjut.

Beberapa Penelitian terdahulu bertemakan kinerja KRPL menunjukkan bahwa KRPL mempunyai dampak positif dan memiliki keberhasilan dalam menghemat pengeluaran konsumsi pangan (Widayanti, 2015 dan Purwantini et al, 2012). Penelitian lainnya menyebutkan bahwa kegiatan pemanfaatan lahan pekarangan belum dapat mendukung ketahanan pangan di tingkat keluarga (Sulaiman \& Wahyuni, 2019). Penelitian lain juga menyebutkan bahwa kelembagaan pada tingkat mikro merupakan basis berkembangnya modal sosial dari bawah, sehingga perlu diperkuat karena berpotensi menjadi penggerak pembangunan sosial (Bulu et al., 2009). Penelitian lainnya mengemukakan bahwa modal sosial dapat dikembangkan dan dioptimalkan dalam bentuk kelembagaankelembagaan sosial di tingkat komunitas yang dapat menguatkan ketahanan pangan pada rumah tangga miskin, dengan mendasarkan pada bounded solidarity yang telah ada antar rumah tangga (Martianto et al, 2009).

Berdasarkan situasi yang telah diuraikan dan paparan penelitian terdahulu, masalah yang dihadapkan pada kedua kelompok wanita tani yang menjadi mitra diantaranya 1) Tidak memiliki modal kerja yang cukup untuk pembukaan lahan, pengolahan tanah, saprotan, dan instalasi pengairan untuk meningkatkan produksi dan ketahanan pangan. 2) Harga jual produk usaha tani yang rendah karena pemberlakuan PSBB, produk usaha tani tidak bisa diserap pasar dan pedagang karena masih terbatasnya ilmu pengetahuan dan keterampilan dalam pemasaran hasil dengan menggunakan pemasaran online. 3) Masih terbatasnya pengetahuan dan keterampilan dalam penangan pasca panen produk pertanian.

Untuk

menyelesaikan permasalahan yang telah dijelaskan, maka telah dilakukan kegiatan Demplot Pemanfaatan Lahan untuk Ketahanan Pangan pada Kelompok Wanita Tani Hegarsari dan Sabilulungan dalam Skema Ketahanan Pangan (PbM-KP). Solusi yang akan diterapkan kepada kedua kelompok tersebut, yaitu: 1) Pendampingan dan pemberian biaya untuk tenaga kerja pembukaan lahan demplot di lahan pekarangan, pembelian sarana produksi pertanian (saprotan), dan alsintan. 2) Membantu pemasaran produk pertanian menggunakan aplikasi pada berbagai platform marketplace (shopee, Tokopedia, facebook, IG), serta menggunakan salah satu perusahaan jasa kirim barang sebagai sarana pengiriman barang agar petani lebih mudah dalam memasarkan. 3) Meningkatkan kemampuan dalam mengemas produk usaha tani menjadi lebih bernilai jual tinggi.

\section{Metode Ilmiah}

Metode kegiatan berupa bimbingan teknis dan pendampingan secara terjadwal. Model pendekatan yang digunakan adalah:

1. Sosialisasi: tim melaksanakan sosialisasi dengan memaparkan pada Kelompok Wanita Tani maksud, tujuan, dan teknis pengabdian yang dilakukan. Setelah itu, semua kelompok wanita tani beserta tim mendiskusikan masalah yang dihadapi dan solusi yang dilakukan dengan pemberian bantuan alat pertanian, 
pendampingan budidaya sayur, pengolahan pasca panen, dan pemasaran produk pertanian.

2. Pemberdayaan Mitra: Kegiatan diawali dengan pemberian alat bantu pertanian, bibit, disertai dengan pendampingan budidaya sayuran. Selanjutnya, kegiatan penyuluhan dan pelatihan pengolahan pasca panen dan pemasaran produk pertanian dengan metode ceramah, tanya jawab dan praktek pembuatan akun marketplace. Sesuai dengan hasil diskusi, maka hasil tani yang dipilih untuk Kelompok Wanita Tani Sabilulungan adalah jagung manis dan Kelompok Wanita Tani Hegarasri adalah singkong, ubi jalar, sayuran (bawang daun, sawi, kangkung, bayam, cabe rawit, bawang merah).
3. Model Pendampingan: kegiatan evaluasi dilakukan dengan cara monitoring pelaksanaan budidaya pertanian secara terus menerus selama 3 bulan oleh tim pengabdian untuk mengetahui kendala yang dihadapi selama budidaya pertanian. Solusi dari masalah yang terjadi akan menjadi bahan diskusi dengan mitra agar di dapat hasil tani yang optimal.

4. Pada tahap kegiatan ini, dilakukan peninjauan kembali hasil pelaksanaan kegiatan, dengan melaksanakan monitoring hasil pertanian dan hasil olahan produk yang telah dihasilkan, setelah pemberian alat, bibit pertanian dan penyuluhan.

Tabel 1.

Metode kegiatan

\begin{tabular}{|c|c|c|c|c|}
\hline $\begin{array}{l}\mathrm{N} \\
\mathrm{O}\end{array}$ & $\begin{array}{l}\text { Bentuk } \\
\text { kegiatan }\end{array}$ & Tujuan & Indikator & Metode \\
\hline 1 & $\begin{array}{l}\text { Pendampingan } \\
\text { budidaya } \\
\text { sayuran }\end{array}$ & $\begin{array}{l}\text { Meningkatkan } \\
\text { produksi } \\
\text { sayuran hijau } \\
\text { dan jagung } \\
\text { manis }\end{array}$ & $\begin{array}{l}\text { Jagung } \\
\text { manis } \\
\text { berbuah } \\
\text { manis } \\
\text { dan } \\
\text { sayuran } \\
\text { hijau } \\
\text { bebas } \\
\text { dari hama } \\
\text { tanaman }\end{array}$ & $\begin{array}{l}\text { Ceramah, } \\
\text { diskusi } \\
\text { dan } \\
\text { praktek }\end{array}$ \\
\hline 2 & $\begin{array}{l}\text { Penyuluhan } \\
\text { tentang cara } \\
\text { pemasaran } \\
\text { produk } \\
\text { pertanian lewat } \\
\text { online di } \\
\text { market place }\end{array}$ & $\begin{array}{l}\text { Menambah } \\
\text { pengetahuan } \\
\text { tentang } \\
\text { pemasaran } \\
\text { lewat online }\end{array}$ & $\begin{array}{l}\text { Tercipta } \\
\text { akun } \\
\text { marketpla } \\
\text { ce }\end{array}$ & $\begin{array}{l}\text { Ceramah, } \\
\text { diskusi } \\
\text { dan } \\
\text { praktek }\end{array}$ \\
\hline 3 & $\begin{array}{l}\text { Pelatihan } \\
\text { pengolahan } \\
\text { pasca panen } \\
\text { jagung dan } \\
\text { sayuran untuk } \\
\text { meningkatkan } \\
\text { nilai jual }\end{array}$ & $\begin{array}{l}\text { Menambah } \\
\text { ketrampilan } \\
\text { petani dalam } \\
\text { penanganan } \\
\text { pasca panen } \\
\text { sayuran }\end{array}$ & $\begin{array}{l}\text { Tercipta } \\
\text { kemasan } \\
\text { yang } \\
\text { kebih } \\
\text { memiliki } \\
\text { nilai jual }\end{array}$ & $\begin{array}{l}\text { Ceramah, } \\
\text { diskusi } \\
\text { dan } \\
\text { praktek }\end{array}$ \\
\hline
\end{tabular}




\section{Hasil dan Pembahasan}

Kegiatan pengabdian masyarakat di masa Pandemi Covid-19 mempuyai tantangan tersendiri bagi tim dosen dalam melaksanakan kegiatan secara langsung.Kegiatan diawali dengan memperkenalkan alat-alat penunjang dan bahan yang digunakan dalam pembuatan demplot kawasan jagung manis dan sayuran dalam rangka ketahanan pangan, yaitu: kangkung, tomat, cabe rawit, sosin dibeli dari kios benih di Singaparna. Ongkos tenaga kerja pembuatan bedengan dan pengolahan tanah. Pengolahan dilakukan oleh anggota tani sehingga mereka memperoleh pendapatan. Besarnya ongkos pengolahan yang diberikan disesuaikan dengan tarif yang berlaku.

Tabel 2.

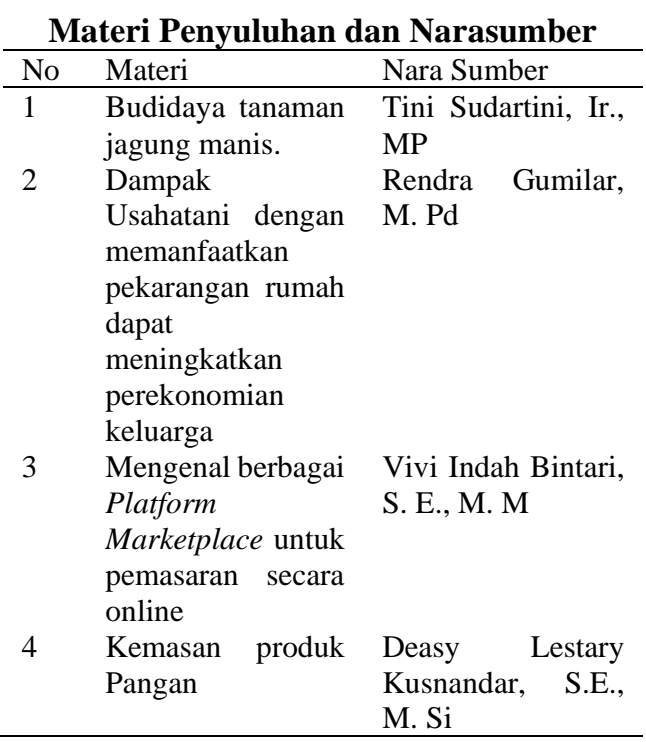

Kedua kelompok tani berhasil membuktikan materi yang telah didapatkan pada saat proses sosialisasi dan pendampingan dimana pengolahan tanah yang digunakan oleh kedua kelompok tani sudah sesuai untuk budidaya produksi jagung manis, seluas 140 bata dengan populasi sekitar 9.000 tanaman. Pengolahan tanah untuk singkong, ubi jalar, sayuran (bawang daun, sawi, kangkung, bayam, cabe rawit, bawang merah) jumlah keseluruhannya seluas 100 bata. Alatalat penunjang yang diberikan, yaitu: selang plastik 1 rol, digunakan untuk menyalurkan air dari sumur ke lapangan, terpal, untuk mewadahi air pada kolam penampungan. Pupuk kandang diperoleh dari kandang yang berasal sekitar mitra 1 dan 2 berupa pupuk kandang domba sebanyak 100 karung. Pupuk NPK 16: 16:16, pupuk Urea, Insektisida dan fungisida dibeli dari kios pertanian. Benih jagung manis hybrid New Lorenza diperoleh dengan membeli secara online, bibit singkong, ubi jalar, bawang merah dibeli dari petani setempat.

\section{Gambar 1. Benih Cabe Rawit, Tomat Dan Jagung Manis \\ Sumber: Dokumentasi Tim PKM, 2020}

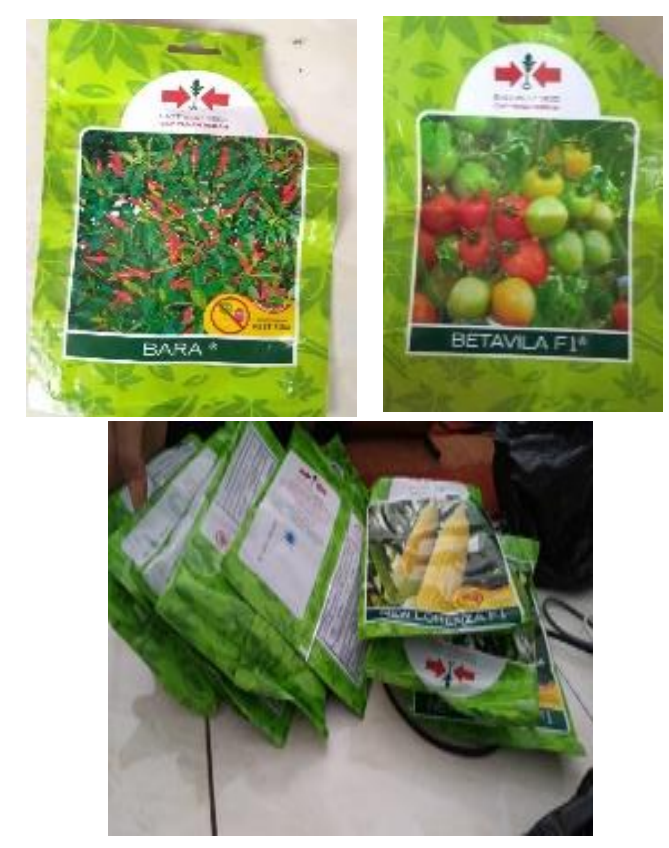



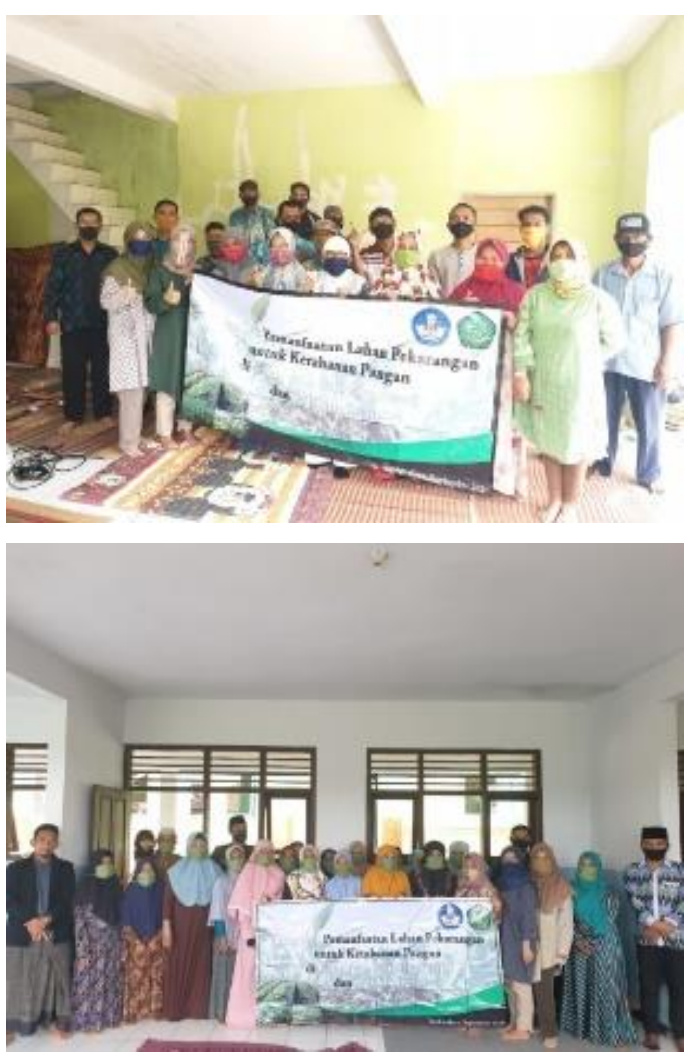

Gambar 2. Foto Bersama Setelah Kegiatan Penyuluhan, Poktan Sabilulungan Dan Kwt Hegar Asri Sumber: Dokumentasi Tim PKM, 2020

\section{Pengolahan Tanah}

Pengolahan tanah dilakukan dengan cara manual menggunakan alatalat pengolahan lahan yang sederhana seperti, sabit, garpu tanah, cangkul, kored dll. Pada saat itu, air hujan belum turun menyebabkan tanah masih cukup keras, sehingga perlu dilakukan penyiraman dari sumber air yang cukup jauh dengan menggunakan selang yang ditampung terlebih daluhu dalam bak penampungan. Proses ini memakan waktu yang relatif lama dan membutuhkan banyak jumlah tenaga kerja. Tenaga kerja yang melakukan proses ini berasal dari anggota poktan Sabilulungan karena semua anggotanya berjenis kelamin laki laki. Pada kelompok wanita tani Hegarasri tenaga kerja di pengolahan tanah dilakukan oleh anggota kelompok tani yang berjenis kelamin laki-laki dan berusia muda. Jumlah orang yang bisa bekerja pada kegiatan ini sebanyak 40 orang. Pengolahan tanah dilakukan sampai tanah tercampur dengan pupuk kandang, strukturnya gembur dan terbentuk guludan atau bedengan penanaman yang disertai dengan saluran drainase.

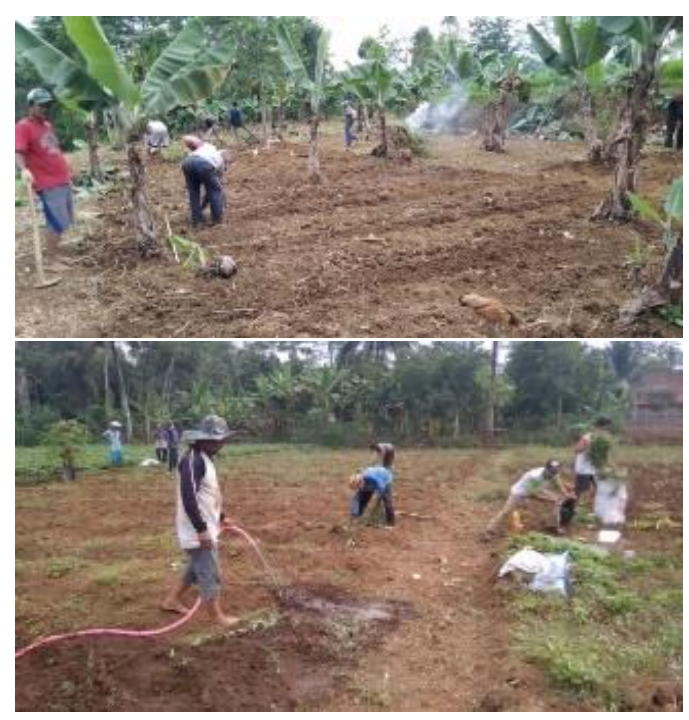

Gambar 3. Pengolahan Tanah Di Poktan Sabilulungan Dan Kwt Hegarasri

Sumber: Dokumentasi Tim PKM, 2020

\section{Pembuatan persemaian benih sosin, pakchoy, tomat, dan cabe rawit.}

Benih-benih yang dilakukan persemaian terdahulu yaitu sosin, pakchoy, tomat, dan cabe rawit. Wadah persemaian menggunakan bekongan daun pisang dengan menggunakan media tanah yang dicampur pupuk kandang. Pembuatan persemaian dilakukan oleh ibu-ibu anggota kwt Hegarasri.

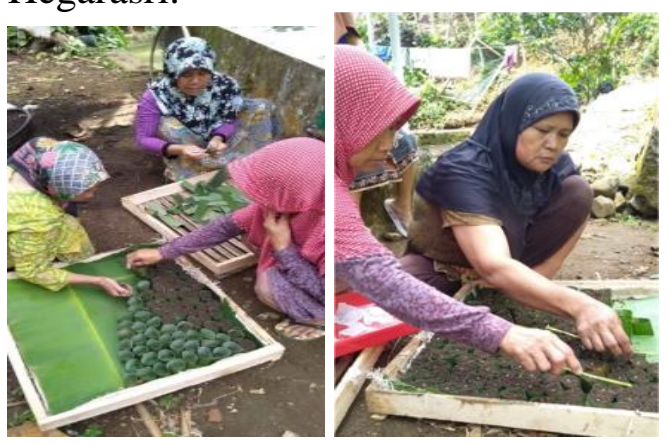

Gambar 4. Persemaian Benih Sawi, Cabe Rawit Dan Tomat

Sumber: Dokumentasi Tim PKM, 2020 


\section{Penanaman}

Jagung manis yang dipakai ialah kutivar New Lorensa ditanam menggunakan jarak $65 \mathrm{~cm}$ ke $25 \mathrm{~cm}$, dengan populasi keseluruhan 9000 tanaman.

Penanaman singkong dan ubi jalar menggunakan stek batang pada guludan yang sudah dibuat. Bawang daun dengan bibit anakan. Kangkung, sosis dan pakchoy ditanam dengan jaraknya $15 \mathrm{~cm}$ x $15 \mathrm{~cm}$.

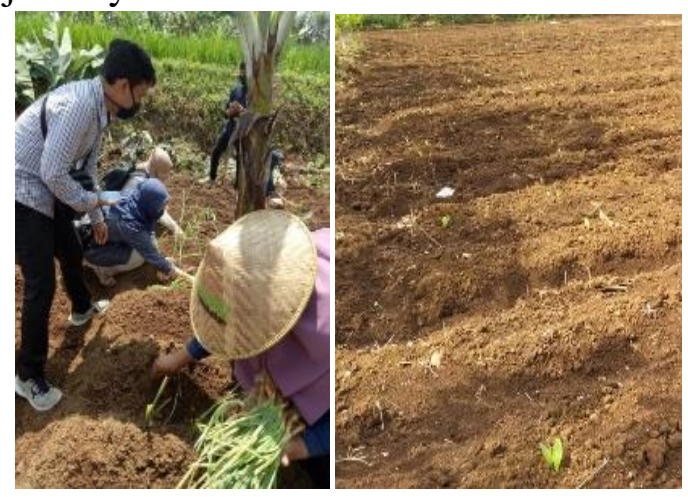

Gambar 5. Kegiatan Penanaman Sumber: Dokumentasi Tim PKM, 2020

\section{Monitoring}

Kegiatan monitoring dilakukan oleh petani, maupun oleh tim pelaksanaa ppm. Monitoring dilakukan terhadap keadaan daya tumbuh tanaman, gejala serangan hama, dan penyakit agar segara ditangani. Monitoring oleh tim ppm dilaksanakan beberapa kali dari awal pertumbuhan tanaman sampai dengan akhir pertumbuhan, dilakukan satu minggu sekali.
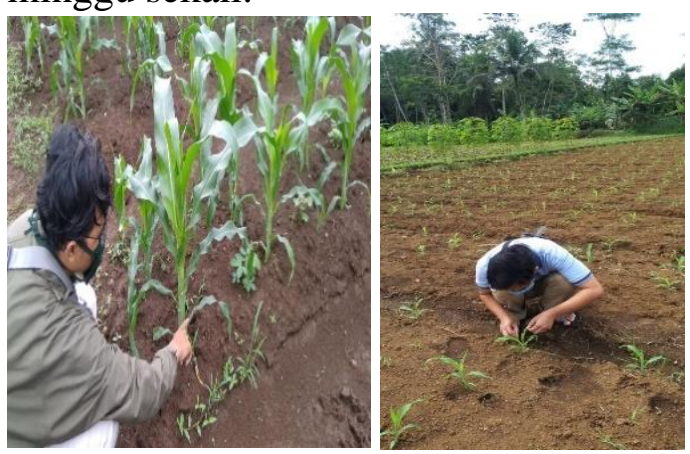
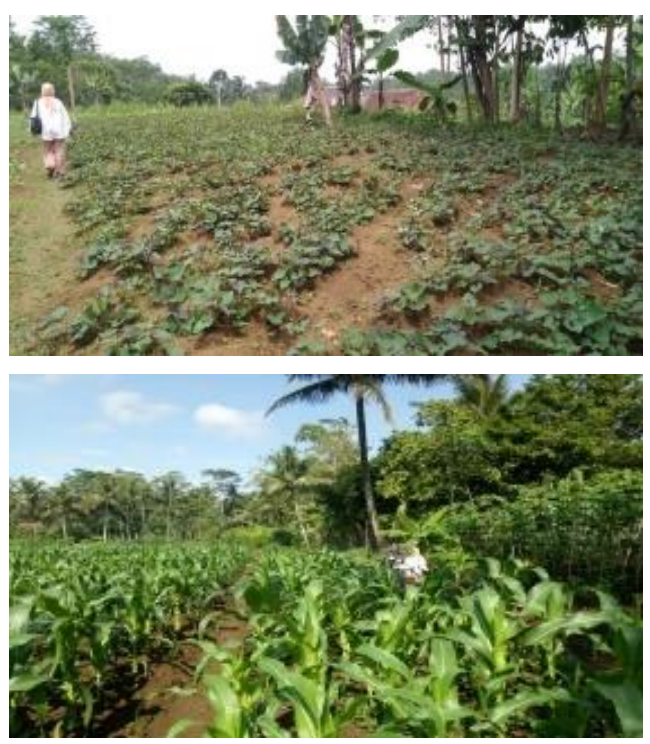

Gambar 6. Kegiatan Monitoring: Pengamatan Hama/ Penyakit, Pertumbuhan Tanaman Sumber: Dokumentasi Tim PKM, 2020

\section{Pemupukan}

Pupuk dasar yang dipakai untuk menambah kegemburan tanah diberikan pada saat pembuatan bedengan. Pupuk kandang yang dipakai yaitu pupuk kandang domba yang banyak tersedia di sekitar tempat pelatihan. Pupuk buatan yang diberikan adalah NPK 16:16:16 untuk jagung manis memiliki dosis 10 g/tanaman, diberikan dengan cara ditugal di sebelah batang tanaman. Pupuk diberikan 14 hari setelah pertumbuhan vegetatif aktif dan pada saat menjelang berbunga umur 35 hari setelah tanam. Pupuk yang dipakai untuk kangkung, sosis, bawang daun ialah pupuk Urea, diberikan di larikan diantara barisan tanaman. 


\section{Penyiraman, Penyiangan dan pembumbunan}

Penyiraman hanya dilakukan pada saat tanaman sampai umur 8 hari setelah tanam (hst), karena hari berikutnya hujan mulai turun. Pembuangan gulma dilakukan dengan cara manual memakai alat kored. Hal tersebut dilakukan, guna melakukan penggemburan tanah dan pembumbunan tanah ke area perakaran tanaman.
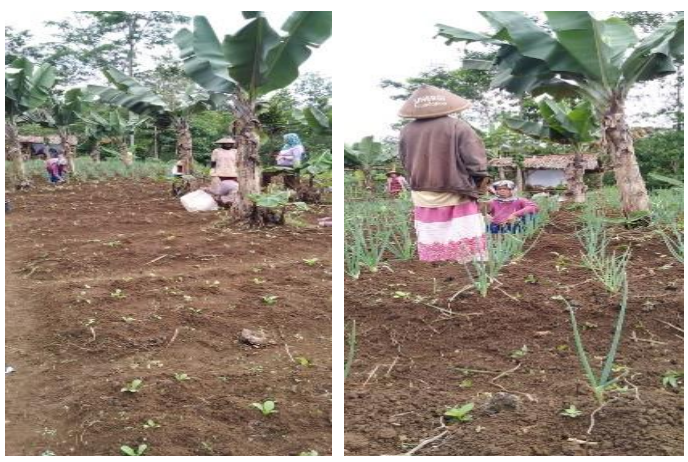

Gambar 7. Kegiatan Pemeliharaan Tanaman Di Kwt Hegarasri

Sumber: Dokumentasi Tim PKM, 2020

\section{Pemberantasan Hama dan Penyakit.}

Pengendalian hama dan penyakit dilakukan sweeping dan monitoring kebun untuk melihat serangan hama dan penyakit. Pada hari ke 16 sudah tampak serangan hama, yaitu ulat grayak (Faw: Fall Aryworm) (Spodoftera frugiperda J. E Smith)
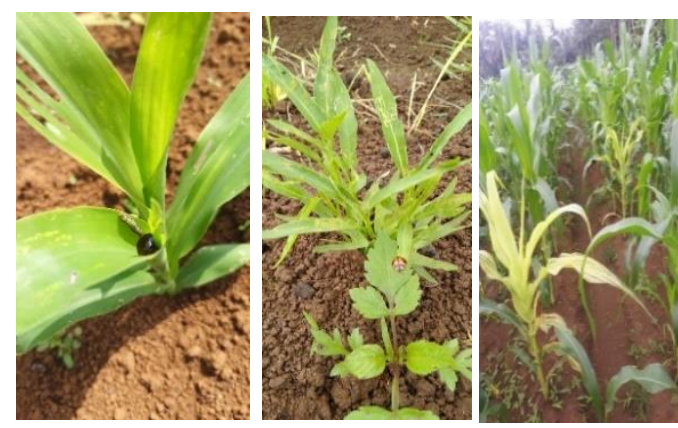

Gambar 8. Hama Ulat Grayak, Kumbang Koksi Dan Penyakit Bulai

Sumber: Dokumentasi Tim PKM, 2020
Hama ini dikendalikan oleh insektisida Prevathon 50 SC dengan cara penyemprotan ke seluruh area penanaman seminggu satu kali. Pengendalian dengan insektisida ini sangat efektif, sehingga penyerangan ulat tidak terlihat lagi. Penyakit bulai mulai terlihat gejalanya pada umur 24 hst, dikendalikan dengan Fungisida Ammestartop. Tanaman kangkung diserang kubang koksi (Epilachna admirabilis) dikendalikan dengan penyempotan insektisida Bestox $50 \mathrm{EC}$.

\section{Penanganan Panen Dan Pascapanen}

Sampai laporan ini dibuat, tanaman yang sudah dipanen, yaitu: sawi, pakcoy, dan bawang daun. Tanaman sosin dipanen dengan cara dicabut beserta akarnya.

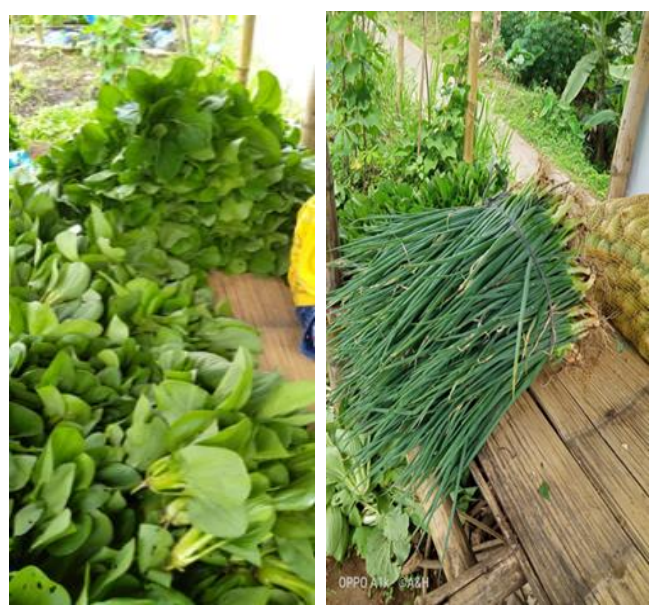

Gambar 9. Hasil Panen Sosin, Pakchoy Dan Bawang Daun

Sumber: Dokumentasi Tim PKM, 2020

Jagung manis sudah dilakukan panen beberapa kali panen. Tongkol jagung yang dihasilkan kualitasnya bagus, tanpa ada biji pada barisan tingkol yang kosong. 

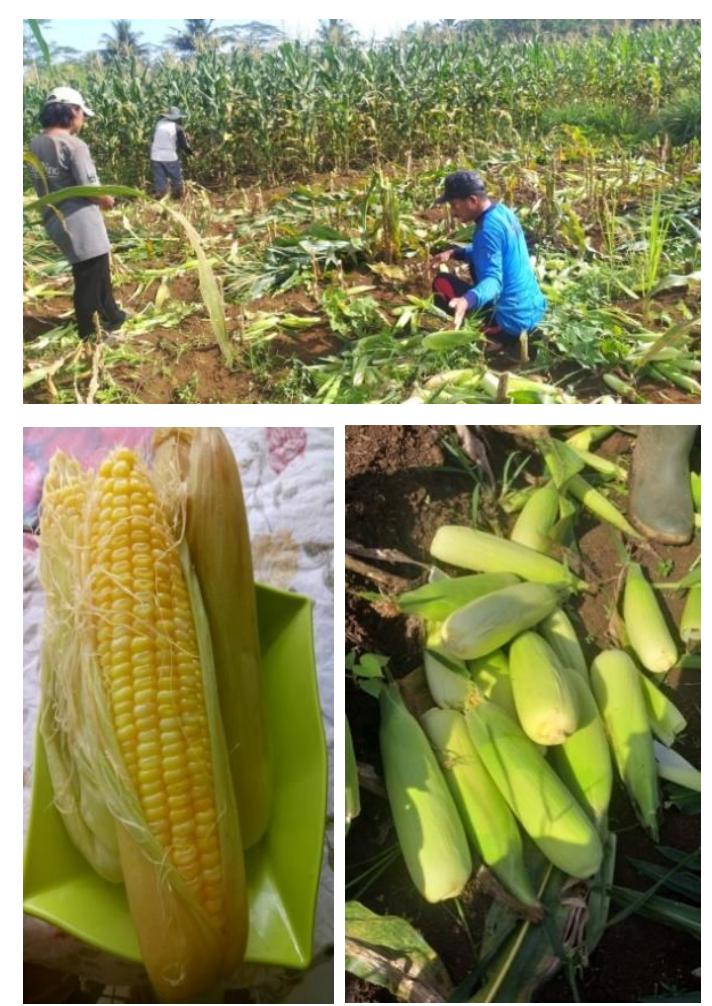

Gambar 10. Panen Jagung Dan Tongkol Jagung Hasil Panen

Sumber: Dokumentasi Tim PKM, 2020

\section{Hasil Panen}

Hasil panen sosin, pakcoy dan bawang terserap semua oleh pasar. Pemasaran sebagian besar dititipkan kepada bandar/pedagang pengumpul sayuran dan sebagaian kecil dengan cara dijual langsung kepada konsumen oleh pedagang keliling di sekitar desa Cibaeud Cigalontang. Pendapatan yang diperoleh dari hasil panen sosis, pakcoy dan bawang daun sebesar Rp502.000,00. Pelatihan packing dan pemasaran yang telah disampaikan dalam penyuluhan tampaknya belum dipraktikan oleh mereka. Keterbatasan sumber daya manusia menjadi hambatan bagi kelompok tani. Kelompok tani tampaknya belum terbiasa untuk mengganti cara tradisional menjadi cara yang lebih modern menggunakan teknologi. Motivasi untuk mengubah kebiasaan kelompok tani dalam memasarkan dengan cara kreatif, penanganan pasca panen dan pengolahan hasil panen, tampaknya harus secara kontinyu dibimbing. Panen jagung manis akan dilakukan satu minggu kedepan dengan perkiraan hasil $2.300 \mathrm{~kg}$ senilai Rp9.200.000,00. Total pendapatan dari hasil panen keseluruhan dengan tanaman singkong dan ubi jalar yang akan dipanen 6 bulan yang akan datang ditaksir senilai Rp11.975.000,00. Pendapatan ini akan dipakai untuk modal usaha tani musim berikutnya. Pemasaran jagung manis sebagaian besar dipesan oleh pedagang pengumpul, pengusaha kuliner, juga ditawarkan dengan memakai platform media sosial seperti Facebook dan Instagram. Akun atas nama kwt Hegar Asri dan kelompok tani Sabilulungan sudah dibuat dan dibimbing penggunaannya.
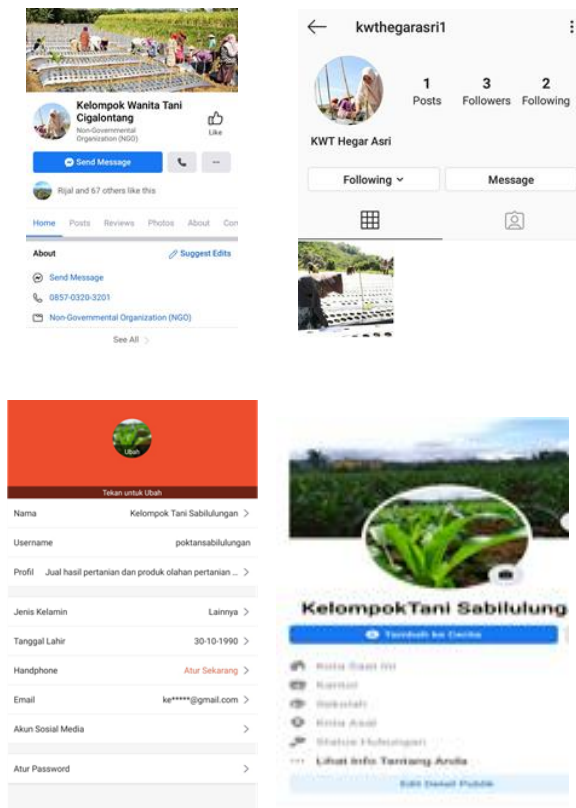

Gambar 11. Akun Kwt Cigalontang Dan Poktan Sabilulungan Di Platform Media Sosial Sumber: Dokumentasi Tim PKM, 2020

\section{Publikasi}

Publikasi kegiatan pelaksanaan PbM-KP telah dilakukan di mass media harian Radar cetak dan Radar digital. Publikasi selanjutnya akan dibuat di jurnal terakreditasi. 

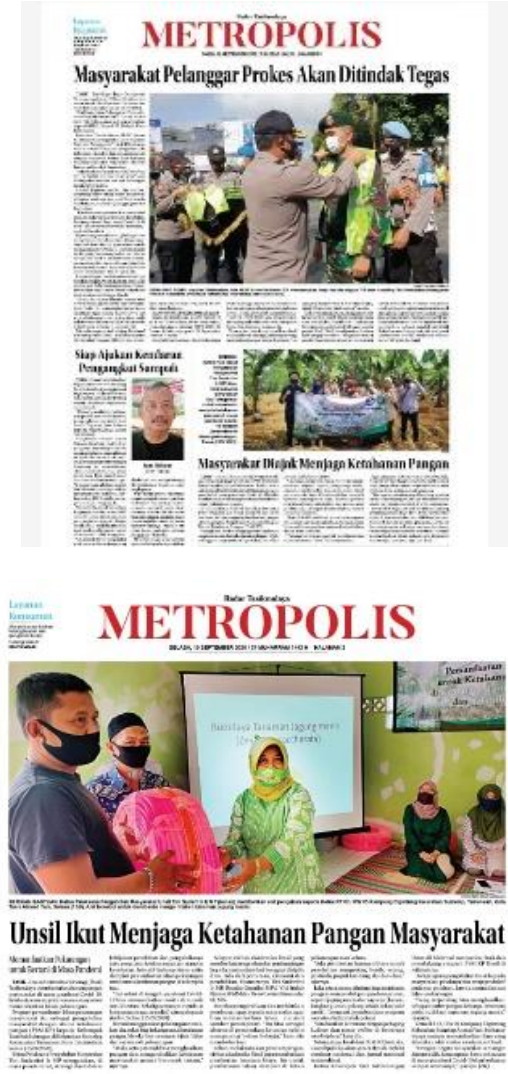

Gambar 12. Publikasi Media Massa

Sumber: Dokumentasi Tim PKM, 2020

\section{Kesimpulan dan Saran}

\section{Kesimpulan}

Kelompok Wanita Tani Hegarsari dan Sabilulungan berhasil memahami pengolahan tanah yang baik, saprotan, dan instalasi pengairan untuk meningkatkan produksi. Kedua kelompok wanita tani juga memahami bahwa produk tanaman hasil panen harus dikemas dengan baik untuk meningkatkan nilai jual dan adanya peningkatan pengetahuan untuk memasarkan produk tanaman secara online dengan menggunakan akun marketplace yang sudah dibuat.

\section{Saran}

1. Para petani sebaiknya bisa mengaplikasikan penerapan materi yang telah disampailkan oleh tim kami sehingga kegiatannya tidak terputus dan hanya terlaksana apabila selama ada pendampingan saja.

2. Pihak Universitas Siliwangi sebaiknya setiap tahunnya memberikan fasilitas untuk pelaksanaan Program Pengabdian Kepada Masyarat dengan tujuan para masyarakat bisa menerima tambahan ilmu untuk diterapkan dalam kehidupannya

\section{DAFTAR PUSTAKA}

Bulu, Y. G., Hariadi, S. S., \& Herianto, A. S. (2009). Pengaruh Modal Sosial dan Keterdedahan Jagung di Kabupaten Lombok Timur Influence of Social Capital and Exposure of Innovation in East Lombok Regency West Nusa Tenggara Province. Jurnal Agro Ekonomi, 27(5), 1-21. http://www.ejurnal.litbang.pertanian .go.id/index.php/jae/article/viewFile /4677/3957

Hegarsari, K. (2019). Anggaran Dasar dan Rumah Tangga Kelompok Wanita Tani Hegarsari Cigalontang. Martianto, D., Alfiasari, ., \& Hadi Dharmawan, A. (2009). Modal Sosial Dan Ketahanan Pangan Rumah Tangga Miskin Di Kecamatan Tanah Sareal Dan Kecamatan Bogor Timur, Kota Bogor). Sodality: Jurnal Sosiologi Pedesaan, 3(1), 125-152. https://doi.org/10.22500/sodality.v3i 1.5869

Purwantini, T. B., Saptana, S., \& Suharyono, S. (2012). Program Kawasan Rumah Pangan Lestari (KRPL) di Kabupaten Pacitan: Analisis Dampak dan Antisipasi ke Depan. Analisis Kebijakan Pertanian, $10(3), \quad 239$. https://doi.org/10.21082/akp.v10n3. 2012.239-256

Sabilulungan, K. T. (2017). Berita Acara Benah Pengurus Kelompok Tani. 
Sulaiman, A. H., \& Wahyuni, E. S. (2019). Strategi Penguatan Modal Sosial Perempuan Tani dalam Pemanfaatan Lahan Pekarangan Terbatas di Kabupaten Bogor. Jurnal Penyuluhan, 15(2), 239-253. https://doi.org/10.25015/penyuluhan .v15i2.27737

Susilowati, S. H., \& Maulana, M. (2012).

Luas Lahan Usahatani dan Kesejahteraan Petani: Eksistensi Petani Gurem dan Urgensi Kebijakan Reforma Agraria Farm Business
Land Size a nd Farmers, Welfare: Smallholders, Existence and Agrarian Reform Urgency Lahan pertanian dewasa ini menghadapi tanta. Analisis Kebijakan Pertanian, 10(1), 28.

Widayanti. (2015). Evaluasi Kinerja Model Kawasan Rumah Pangan Lestari pada Balai Besar Pengkajian dan Pengembangan Teknologi Pertanian Melalui Pendekatan Balance Scorecard. Institut Pertanian Bogor. 